\title{
Supplier Value of Customer-Initiated Product Development: An In-Depth Case Study of a European Industrial Mass-Producer
}

\author{
Anita Friis Sommer, Iskra Dukovska-Popovska, and Kenn Steger-Jensen \\ Institute for Mechanical Engineering and Production, Aalborg University, Denmark \\ \{sommer, shs, iskra, kenn\} @m-tech.aau.dk
}

\begin{abstract}
Increased market demand and shortened product life cycles generate industrial customer requests for collaborative product development. Manufacture-to-stock suppliers struggle to manage the request process to obtain profitability. The purpose of this paper is to investigate if request management is profitable for mass-producing suppliers, and to examine possible relations between profitability of requests and the requesting customer. Through a case study, request management is identified as a profitable process due to long-term accumulated profit from developed products. Request profitability is not identified as related to profitability or turnover of existing customers, and thus profitability of requests cannot be predicted based on these customer data. Results from a coupled interview study indicate that request management has a large potential for future exploitation, and an outline of the supplier value potential of collaborative product development is proposed.
\end{abstract}

Keywords: profitability, supplier value, collaborative product development, supply chain integration.

\section{Introduction}

Increased market demand and shortened product life cycles are generating an increased amount of customer requests for new products [1, 2]. Suppliers struggle to meet these demands and manage collaborative product development. Suppliers must change their innovation strategies from 'innovating for customers' to 'innovating with customers' involving customers in a co-development process [3]. However, the challenge is to combine integration and innovation, responsiveness and flexibility [4]. Some argue that customer co-development cannot reveal innovative customer needs and only generates incremental products [5-7], while others state the opposite that and customer co-creation increases innovation $[8,9]$. Regardless of the innovation level, the topic of crucial importance is whether or not co-development generates long-term supplier value. The most important supplier value in this regard is long-term profitability [10]. Additionally, supplier value in collaborative product development includes reduction in development costs, risks, and development time, and more tacit 
values like achieving a wider range of skills and competencies [11]. Buyer-supplier relationships can also be strengthened through the co-development process [12].

Customer requests for new products must be managed in a go/no-go decision process before co-development can be initiated [13]. Request management includes an assessment of the potential supplier value, however a high level of uncertainty in complex product development complicates value assessment. Therefore, it is questioned if accepting a broader range of requests will increase total supplier value, especially long-term profitability.

Sherden [14] argues that in industrial companies the top $20 \%$ of the buyers generate as much as $80 \%$ of the profits, but that half of these profits are lost because of the bottom $30 \%$ of the buyers who are unprofitable. So far there is only limited research indicating if the same relation is present for co-development processes. Therefore, the aim of this study is to investigate long-term supplier profitability of request management, and how request profitability is related to customer profitability.

The paper is structured as follows: Firstly, the theoretical background is presented, which includes reviews of relevant literature within supply chain integration and collaborative product development. Secondly, the method is described including case presentation, and finally the results are presented and analyzed in a separate section followed by a section containing discussion and conclusion.

\section{Theoretical Background}

Supply chain integration is defined by Bagchi et al [15] as 'the comprehensive collaboration among supply chain network members in strategic, tactical and operational decision-making. Tan and Tracey [16] defines integration in the context of supply chain management as interaction and collaboration between departments and organizations to achieve shared supply chain goals'. The purpose of supply chain integration is to improve performance, where the dominant performance measures are supply chain performance and financial performance [17]. Until recently, the dominant view on supply chain integration has been 'the more, the better'[15]. However, this approach has been criticized and differentiated supply chain integration strategies have been proposed $[4,18]$. They include a change from holistic integration towards selectively integrated, horizontally specialized supply chain processes and capabilities [4]. Hence, integration should be in relation to the context of the supply chain relationship. For suppliers, this entails segmentation according to e.g. customer behavior, product characteristics and lead times [19]. Customers can be segmented according to the ABC segmentation method [2, 3]. Segmentation can be done according to customer size, profitability, and/or business potential among others. The A-segment is the strategically important segment, which is why we consider supply chain integration as relevant mainly for this segment.

\subsection{Collaborative Product Development}

Supply chain integration entails collaboration within different areas [20]. These areas include $\mathrm{R} \& \mathrm{D}$, procurement, inventory management, manufacturing, distribution, supply chain design, and/or supply chain software [15]. Also, collaborative product 
development is an area within supply chain integration [21, 22]. Collaborative product development is defined as 'any activity where two (or more) partners contribute differential resources and know how to agree complimentary aims in order to design and develop a new or improved product'[23, 24]. According to Büyüközkan and Arsenyan [23] collaborative product development consists of three elements: partnership process, collaboration process and product development process. The challenge in collaborative product development is to manage these three processes and the interrelation between them [23]. Suppliers must develop routines and practices to collaborate with customers and internal cross-functional employee teams [25]. However, relationships between companies are subtle and complex and no one recipe exists on how supply chains achieve best performance [4]. Collaborative product development is initiated through a request from one of the supply chain members. In this paper, we look at the situation where the customer is the requestor of a new supplier product or changes to an existing supplier product. From the supplier perspective, collaborative product development then initiates with the customer request, and depending on the potential business value, the supplier accepts or rejects the request. Accepted requests will be developed in collaboration with the customer. The request process for customer-initiated collaborative product development is presented in figure 1:

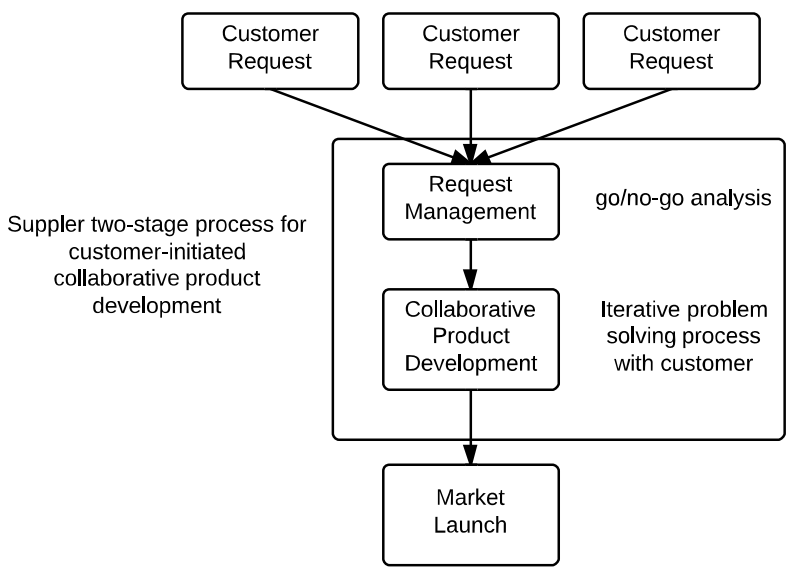

Fig. 1. Customer-initiated collaborative product development

\subsection{Supplier Value in Collaborative Product Development}

The potential benefits of collaborative product development are the acquisition of a wider range of skills and competencies and a reduction in the costs, risks, and time taken to develop products [11]. Naveh [7] suggests that buyer-supplier collaboration is positively related to efficiency but negatively related to innovation, whereas Un et al. [26] finds that collaboration with customers do not appear to facilitate product innovation. This is contradicted by other research findings indicating that efficiency and innovation can co-exist in collaborative product development [27, 28], and that customers are key sources of innovation [8]. 
Hilletofth and Eriksson [2] studies coordination of new product development and supply chain management. They identify four success factors for new product development within four characteristics including market characteristics, product characteristics, strategy characteristics, and process characteristics. The essence is to balance value creation with value delivery [2].

According to Büyüközkan and Arsenyan [23], the motivations for engaging in collaborative product development are:

- $\quad$ Sharing risks, reducing costs

- Technology, knowledge, experience

- $\quad$ Reducing time to market

- Market opportunities, competition

- Expending product family, innovation

- Administrative initiative, corporate culture

As opposed to these findings, the reasons for suppliers engaging in collaboration has been examined by Littler et al. [11]. They find that the main reason for suppliers engaging in customer collaboration is a direct response to customer requests. Hence, whereas a range of motivations for engaging in collaborative product development might be true for customers, suppliers are found to engage in collaborative product development through customer requests, and therefore supplier value of collaborative product development is dependent on request management performance.

Research indicates that top $20 \%$ of customers generate as much as $80 \%$ of the profit, but that half of these profits are lost because of the bottom $30 \%$ of the buyers who are unprofitable [14]. Therefore, suppliers must manage the go/no-go decision process for customer requests, including risk management, impact assessment and business value evaluation. The go/no-go criteria for product development include, among others, project total cost, availability of resources, alignment with strategy, window of opportunity, market acceptance, payback time, and long-term sales growth [29]. Suppliers should carefully choose the right requests for collaborative product development. This is no easy task, since collaborative product development is based on complex problem solving, where the results are hard to predict $[30,31]$. To increase the chances of market success of co-developed products due to radically new innovation, suppliers must be ready to accept innovation failure [32]. Therefore, suppliers have to accept requests with a wide range of innovative ideas to increase the chances of market success. Yet, this approach includes acceptance of risky requests, which contradicts traditional cost-based approaches [33]. Furthermore, it is not certain, that such an approach will generate long-term supplier profit. To our knowledge, no existing research investigates long-term supplier profitability of collaborative product development. Based on the literature review, we suggest that: $A$ broad approach to acceptance of customer requests for collaborative product development is positively related to total supplier profitability.

To the authors, several large industrial suppliers have proposed that collaborative product development should only be for a selected few strategic customers. Strategic customers are often chosen from direct value functions including profit, volume and safeguard (the possibility of 'guaranteeing' a level of business and revenue) [34]. Within lead-user innovation research, it has been found that collaborative innovation 
should be conducted with customers who are front runners of innovation in their respective markets $[35,36]$. We deduced from this body of literature that there might be a relation between the direct value functions of existing customers and the changes of success from collaborative product development with the given customer. This leads us to suggest that: Customer profitability is positively related to the corresponding single request profitability.

The propositions have direct impact on supplier practice and the results will provide basis for guidelines to handle request management for collaborative product development. The theoretical contribution to supply chain integration research is an increased understanding of financial supplier value in collaborative product development.

\section{Method}

The method includes an in-depth case study of a large European industrial massproducer here named Termodyna. The in-depth case study was chosen to develop a rich contextual understanding of collaborative product development based on customer requests, to frame a financial data analysis. Termodyna was chosen as case company because they implemented a request management and collaborative product development process in 2007, and has documented financial performance data of the process and involved customers since that time allowing for a long-term financial analysis. Furthermore, the company has during the entire period chosen a broad acceptance approach in their go/no-decision process, which is one of the main subjects of relational analysis in this paper.

Termodyna allowed for the research team to gain an open access to financial data stored in their ERP-system. The data included turnover and profit for all products and customers, handled through a collaborative product development process, in the 5year period since the process was implemented (2008-2012 both years included). This enabled a long-term financial data analysis including both product and customer specific data. Data on product and customer profitability was extracted for the entire time-span to investigate the financial potential of collaborative product development for a mass-producing supplier. Mapping of the Group Gross Profit (GGP) according to year of request and year of income, generated an accumulated profit overview. In GGP, the cost subtracted from income includes both variable costs and overhead costs. Development costs are not included in the GGP and are currently not measured in Termodyna at the single request level. We estimate, in coherence with Termodyna's process management group, that the main development costs are human resources. In total, the request process employs about 8 full-time employees a year, which is about $€ 650.000$. These development costs have to be contracted the total request profitability measured from GGP to evaluate the total long-term profitability. The second aim is to investigate the proposed relation between customer profitability and request profitability. This was done through a qualitative data analysis comparing five years of profitability statistics for customers and products [37]. The financial data includes all data on products developed through the collaborative product development process and the corresponding customer profitability on additional sales. 
To support the financial data, an interview study has been conducted as part of a larger research study on request management in Termodyna, which provides contextual grounding in analysis of the financial data. The interview study included employees from three internal functions, operations managers, and the process manager. Furthermore, four customers were interviewed, which provided an understanding of the process, customer value and incentives for customers engaging in collaborative product development with the supplier. An overview of the interviews is presented in table 1 .

Table 1. Overview of interviews in each internal function and at the customer.

\begin{tabular}{|l|l|l|l|l|l|}
\hline $\begin{array}{l}\text { Functions / } \\
\text { Interviews }\end{array}$ & $\begin{array}{l}\text { Operations and } \\
\text { process manager }\end{array}$ & $\begin{array}{l}\text { Engine } \\
\text { ering }\end{array}$ & $\begin{array}{l}\text { Technical } \\
\text { Service }\end{array}$ & Sales & Customers \\
\hline $\begin{array}{l}\text { Number of } \\
\text { interviews } \\
(1 \text { hour })\end{array}$ & 4 & 2 & 4 & 4 & 4 \\
\hline $\begin{array}{l}\text { Participants in } \\
\text { group } \\
\text { interviews } \\
(2 \text { X 2 hours })\end{array}$ & 2 & - & 2 & 2 & - \\
\hline
\end{tabular}

The interview study is based on semi-structured interview guide, including openended questions aiming at a detailed description of the process from a holistic viewpoint. Single interviews lasted approximately one hour and group interviews about two hours. All interviews were recorded and notes were made during each session. Afterwards, recordings were transcribed and compared to the notes, and then analyzed using open coding and pattern matching to a theoretical framework on request management [38, 39]. Here, the interview study provides increased understanding of supplier and customer value of collaborative product development, as well as providing the mentioned contextual grounding of the financial analysis.

Termodyna is a large European industrial mass-producer within the automation and control industry, which is globally distributed with manufacturing and/or sales offices on all continents. The company employs more than 30.000 worldwide. The company is traditionally a manufacture-to-stock supplier, offering standard high quality products to manufacturing customers and retailers. About five years ago, the company experienced an increasing amount of requests for new products, varying between 150300 requests pr. year. A request management process was set up in 2007 to consciously manage the requests including collaborative product development, and sales managers were from then on encouraged to send in customer requests for evaluation. Since initiation the company has accepted around $30 \%$ of the incoming requests each year. Evaluation has been conducted ad hoc by a technical service function in company headquarters with a focus on potential profit of each request, considering production costs in relation to sales price and volume. Accepted products are developed in collaboration with customers, typically Original Equipment Manufacturers (OEM)'s, from various industries. Customer interaction varies according to the degree of complexity and uncertainty in the request. Finalized products are registered in the company's SAP system including detailed product and 
customer data. The requests include about $60-70 \%$ simple change requests, $20-30 \%$ large changes to existing products, and $5-10 \%$ classified as new products involving new technology and radical innovation. Collaborative product development is less dominant for simple change requests, however customers may be actively involved through all requests depending on relevance and necessity. The request process is managed by the company through use of a stage-gate process model, presented in figure 2 .

\begin{tabular}{|c|c|c|c|c|}
\hline & & & & \\
\hline Phase 0 & Phase 1 & Phase 2 & Phase 3 & Phase 4 \\
\hline Enquiry & Evaluation & Design and test & $\begin{array}{l}\text { Pre-production } \\
\text { and Final Test }\end{array}$ & Market Launch \\
\hline
\end{tabular}

Fig. 2. Stage-gate request process

\section{$4 \quad$ Results and Analysis}

\subsection{Supplier Profitability of Collaborative Product Development}

The accumulated profit from the five years, show an increasing total profit over the years, which is created by continuous sales from the developed product. The analysis reveals that profitability of requested products is spread over the entire time period, and for most products is still increasing during the first 3-4 years. This indicates that product life in this case has a maturation phase exceeding three years and thus profitability should be considered according to the product life cycle. This corresponds to interview findings that Termodyna's products generally have a product life cycle above 10 years. As mentioned, the GGP used for this analysis does not include development costs. The development costs have been estimated, in collaboration with company management, to be approximately $€ 650.000$ per year. The accumulated GGP for each year are presented in Figure 3.

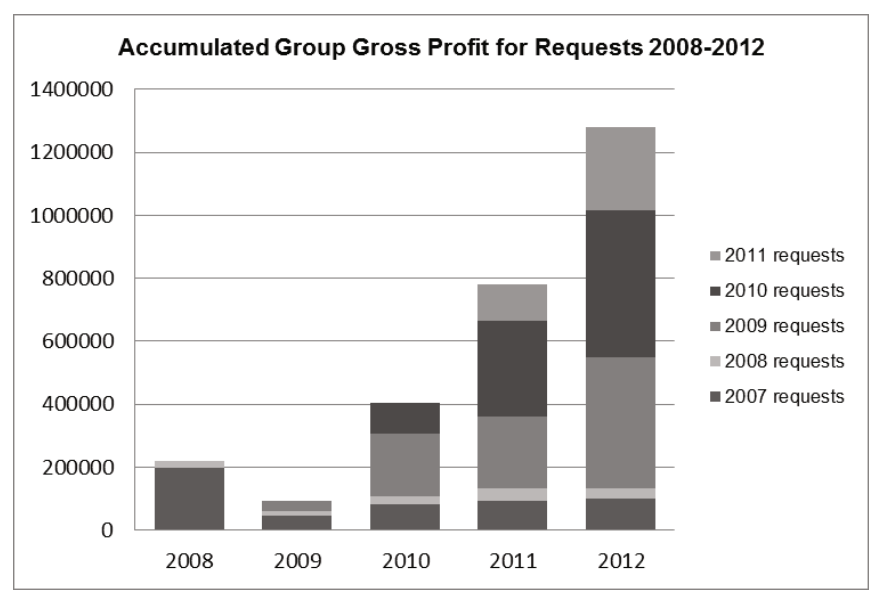

Fig. 3. Accumulated GGP for products from customer requests 2008-2012 (in € ) 
As presented in figure 3, profit from requested products has a potential increase over the years from implementation and exceeded the development costs in the third quarter of 2011. This indicates that implementation of request management will start to be profitable four years after process implementation. This includes total development costs, which contains time spent on all development projects, including those that have either been rejected by customer or supplier. Here it must be noted that about $50 \%$ of the accepted requests in 2007-2009 were never sold. They were at some point rejected by the customer either because they chose a different supplier or the proposed solution did not meet the customer needs. From 2010 and on, the request success rate improved to about $70-75 \%$, due to process management improvement including increased customer integration, increased internal coordination and collaboration, increased efficiency in request management including shorter lead times and decreased redundancy of activities. The improvement results are not necessarily directly related to the increased profitability from 2010-2012, yet it is expected that the initiatives at least have had an indirect effect on profitability through increased request acceptance rates due to increased process efficiency. Through the financial analysis we have found that a mass-producing industrial supplier with a wide acceptance approach to request management can obtain long-term profitability.

Additionally, the case indicates that developing products for existing customers can be a crucial maintenance factor. In the case both sales employees and customers stated that acceptance of requests was a prerequisite for retaining additional sales. Customers require reduction of their amount of suppliers, so suppliers must supply 'the entire package' of products to be competitive. Thus, if the supplier rejects to develop the needed product, the customer will move to another supplier with their codevelopment request and take their orders on standard products with them. One of the interviewed customers had recently had an unsuccessful request, and chose to move to a competing supplier, with their yearly turnover on standard products with a turnover on more than $€ 70.000$. This example highlights the importance of the considerations that must go into rejections in the go/no-go decision process.

\subsection{Customer Profitability and Single Request Profitability}

An analysis was conducted comparing the relation between customer profitability and the corresponding request profitability. We expected a positive relation between the two. However, the analysis showed no linear relation. To highlight this visually, the top 25 customers according to profitability with accepted requests in 2011 have been sorted according to additional sales profit and compared to the corresponding request profit, which is depicted in figure 3.

As an example from figure 4, customer number 25 had additional sales on $€ 1,6$ mill and a request profit on just $€ 970$, whereas customer number 11 had additional sales on about $€ 17.000$ and a request profit on $€ 70.000$. This shows that currently low-segmented customers may provide requests resulting in the highest profitability. This result proved to be highly relevant in practice for Termodyna, who at the time 


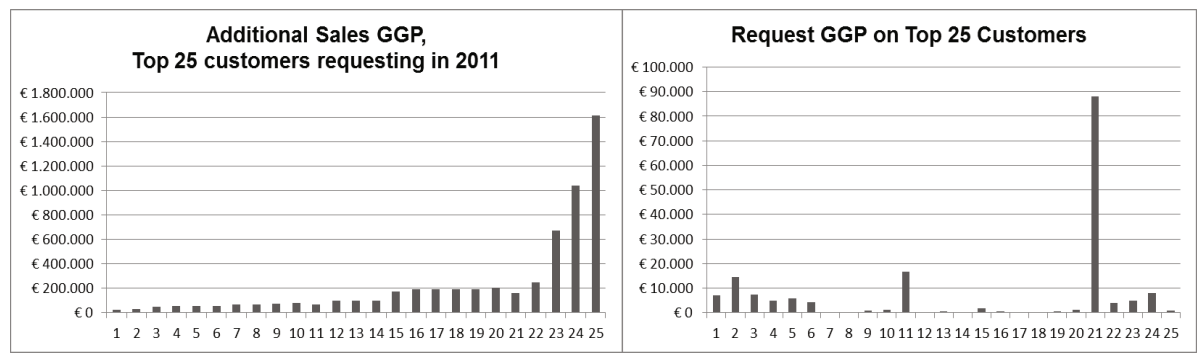

Fig. 4. Top 25 customers; additional sales- and corresponding request-profit

considered rejecting all low segment customers from product development. The analysis suggests that profitable request outcomes cannot be predicted from financial customer data, and thus this relation has been contradicted. Instead, the analysis leads us to suggest that suppliers may benefit from a wide acceptance approach to customer requests.

\section{$5 \quad$ Discussion and Conclusion}

The case study findings show that a broad acceptance approach to request management can be a central part of a long-term profitable collaborative product development process. Suppliers can use this case study as inspiration in handling the increasing amount of customer requests for new products and product changes. The case indicates that implementation of request management for collaborative product development in a mass-producing context can be profitable within four years from implementation, even without considering the potential supplier value gained from knowledge transfer of ideas and domain knowledge from customers. However, a single case study does not have the necessary empirical grounding for generalizability, and therefore more research is necessary to examine if this case study findings have general applicability. A consideration in relation to generalizability is the context and type of case company. This case company is an industrial massproducer and a manufacturer-to-stock company. These suppliers are typically not engaged in collaborative product development compared to engineer-to-order suppliers surviving on customer requests. Furthermore, the involved customers are industrial Original Equipment Manufacturers (OEM)s. This context is important to consider, since both supply chain members have technical product understanding and employed engineers that engage in collaborative product development on similar terms. Therefore, the case study findings are not comparable to either the engineer-toorder supplier context or the context of consumer- or user-integration in product development. Instead, the case provides new findings from the context of massproducing industrial suppliers and their OEM customers.

The case study contributes to supplier practice suggesting a wide acceptance approach to request management. By accepting innovation failure to some extent, suppliers increase the possibility of innovation success. In other words, it might be the smallest of customers that suddenly proposes the one brilliant idea, which changes the 
competitive landscape for the supplier. Therefore, suppliers must stay open-minded and accept collaborative product development failures to some extent. This case study is focused primarily on profitability of collaborative product development, however as existing theory proposes, there are several other potential supplier benefits including obtaining a wider range of skills and competencies and a reduction in the costs, risks, and time taken to develop products [11]. The case shows a large potential for knowledge transfer of product ideas through customer requests, and it seems that the customer-initiated type of collaborative product development withholds additional potential supplier value. Further research is recommended to investigate the difference between types of collaborative product development and the corresponding customer and supplier value.

It was found that request rejection might result in customers changing supplier, including purchase of standard products, whereas request acceptance generates a strategic partnership. Either way, the future buyer-supplier relationship is likely to change based on the outcome. In this way, the request for collaborative product development can be seen as a 'make it or brake it' point for the relationship. If this proves to be a generalizable relation, collaborative product development has a much larger impact on the supply chain than previously considered. Based on this, we question if collaborative product development could be a key driver in supply chain formation and disintegration, and recommend further research to examine this proposal. Based on the discussion of case findings and existing literature, a list of potential supplier value from collaborative product development has been derived. Customer-initiated collaborative product development includes the following potential supplier values:

- Increased profitability

- Strategic relationships

- Transfer of innovative ideas

- Transfer of domain knowledge

- Decreased lead-times

- Increased innovation

- Maintenance of existing customers

The list of supplier values is based on the case study in relation to existing literature, and has not been tested for generalizability. Therefore, future research studies are recommended to test the generalizability of the findings both at a larger scale and within different contexts. Finally, we have a concluding remark on the practical impact of our research, which shows that academic research can make a valuable difference for industrial collaboration partners. During our case study, top management in Termodyna considered termination of collaborative product development and to base new product development solely on the work in the R\&D department, which was decoupled from customer requests. 'We are after all a massproducing supplier' was the leading argument, while they were convinced that collaborative product development was expendable. Our case study changed their 
minds. Now, top management has authorized a major organizational change including process integration between $\mathrm{R} \& \mathrm{D}$ and request management for increased collaborative product development.

\section{References}

1. Butner, K.: The smarter supply chain of the future. Strategy \& Leadership 38, 22-31 (2010)

2. Hilletofth, P., Eriksson, M.D.: Coordinating new product development with supply chain management. Industrial Management \& Data Systems 111, 6 (2011)

3. Desouza, K.C., Awazu, Y., Jha, S., Dombrowski, C., Papagari, S., Baloh, P., Kim, J.Y.: Customer-driven innovation. Research-Technology Management 51, 35-44 (2008)

4. Bask, A.H., Juga, J.: Semi-integrated supply chains: towards the new era of supply chain management. International Journal of Logistics 4, 137-152 (2001)

5. Christensen, C.M., Bower, J.L.: Customer power, strategic investment, and the failure of leading firms. Strategic Management Journal 17, 197-218 (1996)

6. Berthon, P., Hulbert, J.M.: To serve or create? California Management Review 42, 37-58 (1999)

7. Naveh, E.: The effect of integrated product development on efficiency and innovation. International Journal of Production Research 43, 2789-2808 (2005)

8. Bonner, J.M.: Customer interactivity and new product performance: Moderating effects of product newness and product embeddedness. Industrial Marketing Management 39, 485$492(2010)$

9. Atuahene-Gima, K.: An exploratory analysis of the impact of market orientation on new product performance. Journal of Product Innovation Management 12, 275-293 (1995)

10. Lindgreen, A., Wynstra, F.: Value in business markets: What do we know? Where are we going? Industrial Marketing Management 34, 732-748 (2005)

11. Littler, D., Leverick, F., Bruce, M.: Factors Affecting the Process of Collaborative Product Development. Journal of Product Innovation Management, 16-32 (1995)

12. Johnsen, T., Ford, D.: Customer approaches to product development with suppliers. Industrial Marketing Management 36, 300-308 (2007)

13. Sommer, A.F., Steger-Jensen, K.: What and how about customer-driven product development. In: De Koster, R., Van Donk, P.D., De Leeuw, S., Fransoo, J., Van der Veen, J. (eds.) 19th International Annual EurOMA Conference: Serving the World, University of Amsterdam, Amsterdam (2012)

14. Sherden, W.A.: Market ownership: the art \& science of becoming\# 1. American Management Association (1994)

15. Bagchi, P.K., Ha, B.C., Skjoett-Larsen, T., Soerensen, L.B.: Supply chain integration: a European survey. The International Journal of Logistics Management 16, 275-294 (2005)

16. Tan, C.L., Tracey, M.: Collaborative New Product Development Environments: Implications for Supply Chain Management. Journal of Supply Chain Management 43, 2 15 (2007)

17. Fabbe-Costes, N., Jahre, M.: Supply chain integration and performance: a review of the evidence. The International Journal of Logistics Management 19, 130-154 (2008)

18. Jahre, M., Fabbe-Costes, N.: Adaptation and adaptability in logistics networks. International Journal of Logistics: Research and Applications 8, 143-157 (2005) 
19. Godsell, J., Diefenbach, T., Clemmow, C., Towill, D., Christopher, M.: Enabling supply chain segmentation through demand profiling. International Journal of Physical Distribution \& Logistics Management 41, 296-314 (2011)

20. Stonebraker, P.W., Liao, J.: Supply chain integration: exploring product and environmental contingencies. Supply Chain Management: An International Journal 11, 34 43 (2006)

21. Jüttner, U., Christopher, M., Godsell, J.: A strategic framework for integrating marketing and supply chain strategies. The International Journal of Logistics Management 21, 104126 (2010)

22. Fliess, S., Becker, U.: Supplier integration-Controlling of co-development processes. Industrial Marketing Management 35, 28-44 (2005)

23. Büyüközkan, G., Arsenyan, J.: Collaborative product development: a literature overview. Production Planning \& Control 23, 47-66 (2011)

24. Dodgson, M.: Organizational learning: a review of some literatures. Organization Studies 14, 375-394 (1993)

25. Mishra, A.A., Shah, R.: In union lies strength: Collaborative competence in new product development and its performance effects. Journal of Operations Management 27, 324-338 (2009)

26. Un, C.A., Cuervo-Cazurra, A., Asakawa, K.: R\&D Collaborations and Product Innovatio. Journal of Product Innovation Management 27, 673-689 (2010)

27. Lee, A.H.I., Chen, H.H., Tong, Y.: Developing new products in a network with efficiency and innovation. International Journal of Production Research 46, 4687-4707 (2008)

28. Miron, E., Erez, M., Naveh, E.: Do personal characteristics and cultural values that promote innovation, quality, and efficiency compete or complement each other? Journal of Organizational Behavior 25, 175-199 (2004)

29. Carbonellfoulquie, P.: Criteria employed for go/no-go decisions when developing successful highly innovative products. Industrial Marketing Management 33, 307-316 (2004)

30. Stabell, C.B., Fjeldstad, Ø.D.: Configuring value for competitive advantage: on chains, shops, and networks. Strategic Management Journal 19, 413-437 (1998)

31. Pina e Cunha, M., Gomes, J.F.S.: Order and disorder in product innovation models. Creativity and Innovation Management 12, 174-187 (2003)

32. Hamel, G., Breen, B.: The future of management. Harvard Business Press (2007)

33. Tracey, M.: A Holistic Approach to New Product Development: New Insights. Journal of Supply Chain Management 40, 37-55 (2004)

34. Möller, K.E.K., Törrönen, P.: Business suppliers' value creation potential: A capabilitybased analysis. Industrial Marketing Management 32, 109-118 (2003)

35. von Hippel, E.: Lead users: A source of novel product concepts. Management Science 32, 791-805 (1986)

36. Von Hippel, E.: "Sticky information" and the locus of problem solving: Implications for innovation. Management Science, 429-439 (1994)

37. Arbnor, I., Bjerke, B.: Methodology for creating business knowledge. SAGE Publications Ltd., London (2008)

38. Yin, R.: Case Study Research: Design and Methods. Sage, CA (1994)

39. Auerbach, C.F., Silverstein, L.B.: Qualitative data: An introduction to coding and analysis. New York University Press, New York (2003) 